Wiggers, üler Terpentinlampher.

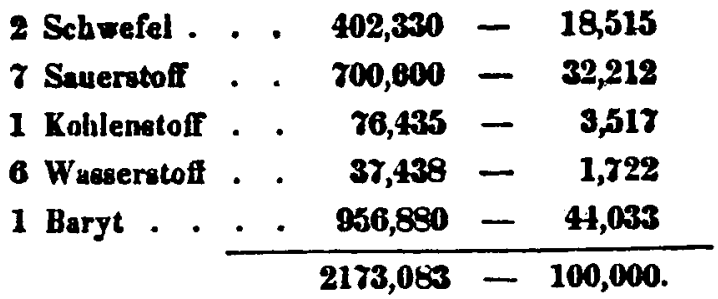

Man kann sich dieses Salz zusammengesetzt denken als eine Verbindung von schwefelsaurem Baryt mit Schwefelsänre oder schwefliger Süure und Wasser mit einem Kohlenwazserntoff:

$\mathrm{SO}_{3}+\mathrm{BaO}+\mathrm{SO}_{3}+\mathrm{CH}_{4} \mathrm{O}=\mathrm{SO}_{3}+\mathrm{BaO}+\mathrm{SO}_{2}+\mathrm{CH}_{2}+2 \mathrm{aq}$.

Ueber die krystallisirte Substanz aus dem Terpentinöl; ron A. Wiggers.

Bekanntlich ist die Gewinnung der krjstallisirten Subatma, wolche sich bisweilen ans dem Terpentinōl abzusetzen pilegt and welche so zusammengesetst ist, dafs man sie als ein $\mathrm{Hy}$ drat des Terpentinöls betrachten könnte, bisher nur ron $\mathrm{Za}$ falligkeiten abhängig gewesen, wobei immer nor sehr kleine Mengen erhalten worden. Ieh habe jetzt eine Methode gefonden, wach welcher man diesen interessenten Körper in beliebig grofsen Mengen erhalten kann, nach welcher man also die Umwandlang des Terpentinöls in denselben in der Gewalt hat.

In der Gegend von Bremen wird nämlich von Thierärzten ein Gemisch ron Terpentinöl, Alkohol, Salpetersäure and einer höchst geringen Menge Sascofrasoll angewendet. In diesem Gemiech hatte Herr Martfeld, Provbor der 
Ueber dis medicinischo Wirksankeit des Amygdalins. 350

Apotbeke zu Ottersberg bei Bremen, die Bildung von Krystallen bemerkt, woron er-mir im September 1839 eine kleine Parthie sur Untersuchung mittheilte. Ich fand sehr bald, dofs wie der bereits bekannte sogenannte Terpentincampher waren. Ich bin hierdurch veranlaf́st worden, über die Ursache der Bildung and über die chemischen Verhältnisse diese Körpers eine Untersuchung rorzunehmen, die mich schon seit jener Zeit beschätigt und deren Resultate ich recht bald mittheilen su können hoffe. Ich will hier nur so viel anführen, dafs man diesen Körper unzenweise erhalten kann, wenn man Terpentinöl mit Salpetersäure, am besten mit Alkobol, in gewissen Verhältuissen vermischt und monatelang stehen läfat, und dafs es die Modification des Terpentinöls, welche mit Salsänre die krystallisiste Verbindung bildet, zn seyn scheint, welche unter den obigen Umständen in den eogenannten Terpentincampher umgewandelt wird.

\section{Ueber die medicinische Wirksamkeit des} Amygdalins.

Bei der allgemeineren Anfmerksamkeit, welche jetzt der Anwendung des Amygdalins, in Verbindung mit MandelEmulsion, an der Stelle der medicinischen Blausäure - Präparate, von Seiten der Aerzte geschenkt zu werden anfänt, halten wir es für angemessen, an einige frühere Versuchs liber die Wirksarkeit des Amygdalins auf den lebenden 0 rganiemus su erinnern, die uns bei der Publikation unserer Untermchnngen über die Bildung des Bittermandelöls gänzlich entgangen waren und jetzt jedenfalls alle Aufmerksamkeit reedienen, de mit Bestimmbeit darans herrorzugehen scheint, 